\title{
Inter-sexual differences in New Zealand fur seal diving behaviour
}

\author{
Brad Page $^{1,2, *}$, Jane McKenzie ${ }^{1}$, Simon D. Goldsworthy ${ }^{1,2}$ \\ ${ }^{1}$ Sea Mammal Ecology Group, Zoology Department, La Trobe University, Bundoora Campus, Victoria 3086, Australia \\ ${ }^{2}$ Present address: South Australian Research and Development Institute (Aquatic Sciences), PO Box 120, Henley Beach, \\ South Australia 5022, Australia
}

\begin{abstract}
We studied the diving behaviour of adult male and lactating female New Zealand fur seals Arctocephalus forsteri to determine inter-sexual differences in their foraging strategies. Adult male fur seals are significantly longer and heavier than lactating females. Lactating females are central place foragers that regularly provision dependent pups, and consequently females conducted shorter duration foraging trips $(5.0 \pm 3.7 \mathrm{~d})$ compared to the relatively unconstrained adult males $(9.0 \pm 3.9 \mathrm{~d})$. Male trip durations were not correlated to variables that measured individuals' dive effort. In lactating females, foraging trip duration was significantly, positively correlated to the number of dives $\mathrm{h}^{-1}$ and negatively correlated with the mean dive duration at night. This indicates that females on longer trips invested relatively more time searching for prey patches, which they utilised on relatively short duration dives. Males and females typically dived at night and appeared to utilise both pelagic and benthic habitats. Males dived deeper $(\max =380+\mathrm{m}$, mean $=52.1 \pm 59.3 \mathrm{~m})$ and for longer $(\max =14.8 \mathrm{~min}$, mean $=3.6 \pm 2.5 \mathrm{~min})$ than females $(\max =312 \mathrm{~m}$ and $9.3 \mathrm{~min}$, mean $=41.5 \pm 26.8 \mathrm{~m}$ and $2.7 \pm 1.3 \mathrm{~min}$ ). Inter-sexual foraging competition is likely to be minimal in this species, because females typically utilised continental shelf waters and males foraged in deeper waters over the continental shelf break, beyond female foraging grounds. Inter-sexual differences in fur seal diving behaviour most likely result from sexual dimorphism, which places different physiological constraints on the diving performance of males and females.
\end{abstract}

KEY WORDS: Arctocephalus $\cdot$ Sexual segregation $\cdot$ Foraging ecology $\cdot$ Resource partitioning Resale or republication not permitted without written consent of the publisher

\section{INTRODUCTION}

Animals frequently assess their circumstances and trade-off where and when to forage, rest and/or breed in an attempt to maximise their survival and reproductive success (Clutton-Brock et al. 1982). Ultimately, foraging ability and food availability dictate foraging success, and this determines how much energy individuals can set aside for reproduction. The strategies that individuals employ to acquire and allocate their limited resources can vary temporally and spatially (e.g. Sol et al. 2000), but they are also subject to evolutionary constraints, which can differ according to the social status, age and sex of individuals (Clutton-Brock et al. 1982).

In sexually dimorphic species, 2 hypotheses are commonly used to explain the evolution of behavioural dif- ferences in resource exploitation by adult males and females: the ecological divergence and intra-sexual competition hypotheses (Stewart 1997). The 2 hypotheses are not mutually exclusive, and both result in reduced intra-specific competition for resources. The ecological divergence hypothesis suggests that sexual dimorphism evolves as a consequence of males and females utilising different resources, which may be different-sized prey or different habitats (e.g. Shine et al. 2002). In contrast, the intra-sexual competition hypothesis implies that sexual dimorphism evolves as a consequence of sexual selection and intra-sexual competition. For example, adult female northern elephant seals Mirounga angustirostris forage in different regions of the Pacific Ocean to their adult male counterparts, which must utilise foraging grounds with more 
energy-rich prey to increase their competitive ability against other males. Natural selection then operates because large males increase their reproductive opportunities by out-competing small rivals for access to females in oestrus (Stewart 1997).

The different foraging strategies employed by conspecific males and females have been studied in several species. For example, sex differences have been related to bill dimorphism in birds (Radford \& Du Plessis 2003), gape size in sea-snakes (e.g. Shine et al. 2002), the diet and hunting group size in lions (Funston et al. 1998), the costs and benefits associated with storing and transporting body fat in phocid seals (Beck et al. 2003) and the diet of fur seals (Page et al. 2005a).

The foraging ecology of lactating female otariids (fur seals and sea lions) has been investigated in several species and our understanding of otariid foraging ecology is largely drawn from these studies. Female otariid behaviour has been extensively studied because females are a critical demographic component of otariid populations (males do not help to raise pups) and because they are readily accessible whilst lactating (Harcourt et al. 1995, 2002, Arnould \& Hindell 2001, Robson et al. 2004). Female otariids nurse their pups for 4 to 36 mo before weaning and during this time perform multiple foraging trips, which are constrained in duration by their pups' fasting abilities. As predicted by central-place foraging models, fitness in lactating otariids will not always be maximised by foraging in the most productive regions, but rather, by milk delivery rates to their dependent pups (Orians \& Pearson 1979). Accordingly, females would be expected to forage as close to the colony as possible, provided sufficient energy can obtained to more than offset the cost of the round-trip (Orians \& Pearson 1979).

Female otariids are generalist predators, whose diet is influenced by both prey availability and the metabolic demands of gestation and lactation (Fea et al. 1999, Harcourt et al. 2002, Page et al. 2005a). Most lactating otariids dive at night and utilise vertically migrating prey, with dives typically deeper around sunset and sunrise and shallower around midnight (Gentry et al. 1986). However, some lactating otariids dive throughout the day and night and utilise benthic prey (Gentry et al. 1986, Goebel et al. 1991, Costa \& Gales 2000, Arnould \& Hindell 2001).

Adult male otariids are at least twice the mass of adult females and consequently males have different physiological constraints and metabolic requirements compared to females (Costa 1991). Furthermore, male and female otariids have been shown to utilise different prey (e.g. Page et al. 2005a) and they employ dramatically different strategies to maximise their survival and reproductive success (Gentry et al. 1986). Because males do not help raise pups they need only return to land to rest, avoid predators, moult and breed. Accordingly, males would be expected to either exploit deeper habitats in the same region as females or spend longer at sea and travel further afield than females, because the increased time available for travel could get them to more profitable foraging grounds.

Male otariid foraging behaviour has received little attention, with just 5 foraging behaviour studies conducted to date (Green 1997, Hindell \& Pemberton 1997, Boyd et al. 1998, Campagna et al. 2001, Kirkwood et al. 2002). The foraging behaviour of Australian fur seal males Arctocephalus pusillus doriferus was found to be similar to that recorded for females-most dives by males went to the bottom, lasted 2 to $3 \mathrm{~min}$ and occurred throughout the day and night (Hindell \& Pemberton 1997, Kirkwood et al. 2002). Although foraging trip durations were similar for males and females, some males foraged further from the colony (Arnould \& Hindell 2001, Kirkwood et al. 2002). The foraging behaviour of male and female Antarctic fur seals A. gazella was compared at South Georgia (Boyd et al. 1998) and Heard Island (Green 1997). At both localities males foraged further from the colony and dived deeper than females, but at South Georgia very few dives by either sex went below $100 \mathrm{~m}$, indicating that both sexes utilised prey in the water column (Boyd et al. 1998). At Heard Island, adult male Antarctic fur seals typically dived during the day and night, whereas lactating females dived almost exclusively at night (Green 1997). Males utilised shelf waters around the island or pelagic waters south of the island, and females foraged over shelf and shelf break waters to the northeast of the island (Green 1997). Inter-sexual differences in South American sea lion Otaria flavescens foraging locations were examined in a study of 2 adult males and 20 females (Campagna et al. 2001). Males and females foraged on the continental shelf; however, males travelled further from the colony and spent longer at sea on each trip. Results from these studies suggest that males typically forage further afield, spend longer at sea and dive deeper than females. Such differences are not unexpected, given the marked differences in body size and roles in pup rearing.

Similarly, we predicted that intra-sexual competition for females and the constraints that lactation imposes on females would be reflected in inter-sexual differences in New Zealand fur seal Arctocephalus forsteri diving behaviour. To test this hypothesis we predicted that males would perform deeper, longer duration dives and longer duration foraging trips compared to adult females. We also predicted that females would exert greater dive effort, in an attempt to minimise the distance and time away from their pups. To examine these hypotheses, we recorded NZ fur seal diving behaviour using data-logging time-depth recorders. 
As dive records were collected over several seasons, we also describe intra-sexual and seasonal variation in NZ fur seal foraging behaviour, which may reflect temporal or spatial variation in prey availability.

\section{MATERIALS AND METHODS}

Study site. The study was conducted between July 2000 and August 2002 at the Cape Gantheaume Conservation Park on the south coast of Kangaroo Island, South Australia (36 $\left.04^{\prime} \mathrm{S}, 137^{\circ} 28^{\prime} \mathrm{E}\right)$ (Fig. 1). The continental shelf to the south of Cape Gantheaume is typically 60 to $90 \mathrm{~m}$ deep and the nearest continental shelf edge (150 $\mathrm{m}$ depth contour) and pelagic waters (>2000 m depth) are located $70 \mathrm{~km}$ and $85 \mathrm{~km}$ south of Cape Gantheaume, respectively (Fig. 1).

Capture and restraint. In 2000, randomly selected lactating females were captured using a hoop-net and given Midazolam ${ }^{\circledR}$ (intramuscular: 0.15 to $0.40 \mathrm{mg} \mathrm{kg}^{-1}$, Hypnovel $^{\circledR}$, Roche Products) to reduce capture stress and facilitate anaesthetic induction. Anaesthesia was induced and maintained using Isoflurane ${ }^{\circledR}$ (Veterinary Companies of Australia), administered via a portable gas anaesthetic machine (Komesaroff small animal anaesthetic machine, Medical Developments Australia). A mask was held in place over each seal's nose and mouth, which was connected to the gas anaesthetic machine. To reduce capture stress in 2001 to 2002, randomly selected adult females were given Zoletil ${ }^{\circledR}$ (intramuscular: $\sim 2.0 \mathrm{mg} \mathrm{kg}{ }^{-1}$, Virbac) prior to capture —administered using 0.5 cc barbless darts (Pneu-Dart ${ }^{\circledR}$ ), fired from a $\mathrm{CO}_{2}$-powered tranquilliser gun (Taipan 2000, Tranquil Arms). Anaesthetised adult females were then captured using a hoop-net and restrained by 1 to 2 people, because initial restraint stimulated a flight response in all but a few deeply anaesthetised seals. No Midazolam ${ }^{\circledR}$ was used on seals that were given Zoletil ${ }^{\circledR}$, but in most cases anaesthesia had to be maintained using Isoflurane ${ }^{\circledR}$. Adult males that appeared to be large enough to defend breeding territories during the breeding season were lightly anaesthetised using Zoletil ${ }^{\circledR}$ (intramuscular: $~ 1.5 \mathrm{mg} \mathrm{kg}^{-1}$, 1.0 cc barbless darts: Pneu-Dart $\left.{ }^{\circledR}\right)$, captured using a hoop-net, restrained by 2 to 4 people and deeply anaesthetised with Isoflurane ${ }^{\circledR}$ using the equipment and methods outlined above.

Data collection. Anaesthetised seals were weighed with a spring balance $(50 \pm 0.1 \mathrm{~kg}$ or $200 \pm 1.0 \mathrm{~kg}$, Salter) and their standard body length (nose to tail) was taken with a tape measure $( \pm 1 \mathrm{~cm})$. Individually numbered plastic tags (Supertags ${ }^{\circledR}$, Dalton) were applied to the trailing edge of each foreflipper. To determine the age of seals a post-canine tooth was removed using dental elevators (females: $3 \mathrm{~mm}$, males: $5 \mathrm{~mm}$ ). To provide short-term pain relief a local anaesthetic $(0.7 \mathrm{ml}$, Lignocaine ${ }^{\circledR}$, AustraZeneca) was injected in the gum beside the post-canine. Ages were estimated by counting growth layer groups in the cementum of decalcified and stained longitudinal sections of post canines,

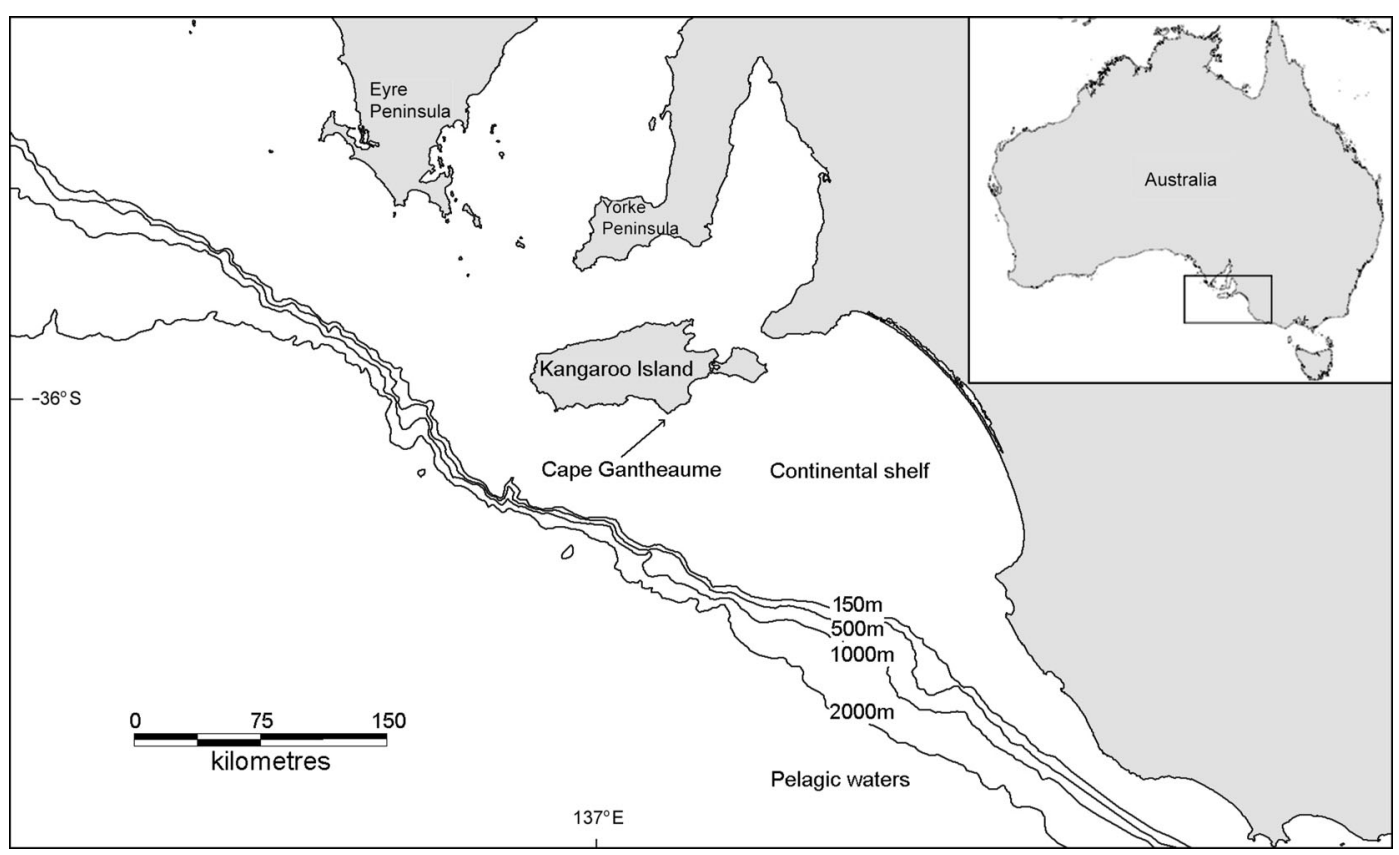

Fig. 1. Location of Cape Gantheaume in relation to the continental shelf, shelf break (150, 500, 1000 and $2000 \mathrm{~m}$ depth contours) and pelagic waters 
using methods adapted from Stewart et al. (1996). The aging technique was validated on post-canine teeth, which were collected from 22 known-age NZ fur seals. Age was correctly assigned to 17 (77\%) of the knownaged individuals and underestimated by 1 yr for the other 5 individuals (23\%) (J. McKenzie unpubl. data).

Time-depth recorders (TDRs, Mk7, Wildlife Computers) were deployed on 27 females and 13 males, of which 26 and 13 were recovered. Time-depth recorders had a resolution of $\pm 1 \mathrm{~m}$ and sampled dive depth every $5 \mathrm{~s}$ (females: $\mathrm{n}=26$, males: $\mathrm{n}=10$ ) or every $10 \mathrm{~s}$ during initial deployments on males $(n=3)$. A wet/dry sensor indicated when seals commenced and ended foraging trips. All TDRs were concurrently deployed with KiwiSat satellite transmitters (Sirtrack). In 2000, the TDR and KiwiSat units were glued to the fur on the dorsal midline between the scapulae, using a hardsetting epoxy (Araldite 268, Ciba Specialty Chemicals) $(n=8)$. One of these seals returned to the colony without the units and 3 others appeared to almost be detached when retrieved. In 2001 and 2002, the units were glued to the fur on the dorsal midline $\sim 5 \mathrm{~cm}$ posterior of the trailing edge of the foreflippers using a flexible-setting epoxy (Araldite 2017, Vantico) $(n=32)$. These units appeared to be well attached to the fur when they were retrieved.

Data analyses. To avoid potential biases arising from the different number of foraging trips recorded, data from the second and subsequent foraging trips were not used to examine inter-individual and seasonal variation. Pressure transducer drift was corrected using software supplied by the TDR manufacturer, which also calculated some dive parameters (Wildlife Computers Beta Instrument Manager v0.91). We limited potential foraging behaviour to dives greater than $4 \mathrm{~m}$, because shallow dives are thought to be associated with travelling behaviour and/or caused by waves, in accordance with previous studies (e.g. Arnould \& Hindell 2001). Dive bottom time (DBT) was calculated as the time spent below $85 \%$ of each dive's maximum depth, in line with other studies (e.g. Mattlin et al. 1998).

Dives were visually examined and individually classified based on their time-depth profiles (Fig. 2) into 3 types: foraging, drifting and departure/arrival dives (Arnould \& Hindell 2001, Page et al. 2005b). Foraging dives appeared to be either V-shaped (having little DBT) or U-shaped with or without wiggles (vertical migrations) at their maximum depth (Fig. 2). Similar vertical migrations at the bottom of dives are present in the dive records of many seal species and possibly reflect behaviour when seals are pursuing prey (e.g. Le Boeuf et al. 1992). The maximum depth of some Ushaped dives appeared to be constrained by the seafloor, however not all U-shaped dives appeared to be benthic dives (Fig. 2). Drift dives were classified based on their rapid descent phase, when the seal actively swims, followed by a slower descent (drift) period, during which time the seal does not actually swim (Crocker et al. 1997, Page et al. 2005b, Fig. 2). The drift phase ended when the seal swam toward the surface (Fig. 2). Departure and arrival dives were classified as dives that appeared to be limited in depth by the seafloor and occurred just prior to hauling out at the colony or immediately after departure (Fig. 2). We excluded departure/arrival dives and drift dives $(<1 \%$ of dives) from analyses of dive depths and bottom times, to focus comparisons on putative foraging dives (>99\% of dives), when seals are thought to search for prey. If foraging trip duration exceeded $3 \mathrm{~d}$, at least 3 entire days (midnight to midnight) were randomly selected for dive classification as initial analyses indicated that $3 \mathrm{~d}$ adequately represented individual variation (Table 1). All dives were classified if foraging trips lasted fewer than $3 \mathrm{~d}$ (Table 1).

To examine diving variability, 13 parameters were calculated for each foraging trip, some of which have been used in other studies (e.g. Lea et al. 2002). The 13 diving parameters were also calculated relative to their occurrence during night and day, giving 39 parameters for multivariate dive analyses. Night and day was calculated based on sunrise and sunset times at Cape Gantheaume (Geoscience Australia software, Department of Industry Tourism and Resources, Canberra, Australia). The diving parameters were: (1) mean dive depth (m), (2) mean dive duration (min), (3) proportion of time submerged (sum of dive duration proportional to trip duration; \%), (4) median dive depth (m), (5) median dive duration (min), (6) proportion of time at the bottom of dives (sum of DBT proportional to trip duration; \%), (7) mean DBT (min), (8) dive frequency (number of dives $\mathrm{h}^{-1}$ ), (9) vertical depth $\mathrm{h}^{-1}$ (2 times the cumulative dive depth for the entire trip divided by trip duration; $\mathrm{m}),(10)$ mean wiggle distance $(\mathrm{m}),(11)$ mean number of wiggles $\mathrm{h}^{-1}$ (number of wiggles divided by trip duration), (12) mean descent rate (rate of change in depth from surface to bottom of dive), (13) mean ascent rate (rate of change in depth).

Semi-strong hybrid multi-dimensional scaling (MDS) was employed for multivariate analyses of the diving parameters to compare between individuals, seasons and sexes, using the PATN Analysis Package (Division of Wildlife \& Ecology, CSIRO). The Bray \& Curtis association measure was used for the analysis, because it is an effective method for analysing multivariate ecological data (Beals 1984). A non-hierarchical agglomerative fusion strategy was used to produce a dendrogram based on the 39 diving parameters and objectively classify seals into behavioural dive groups (BDG), following the methods of Lea et al. (2002). A scree plot 

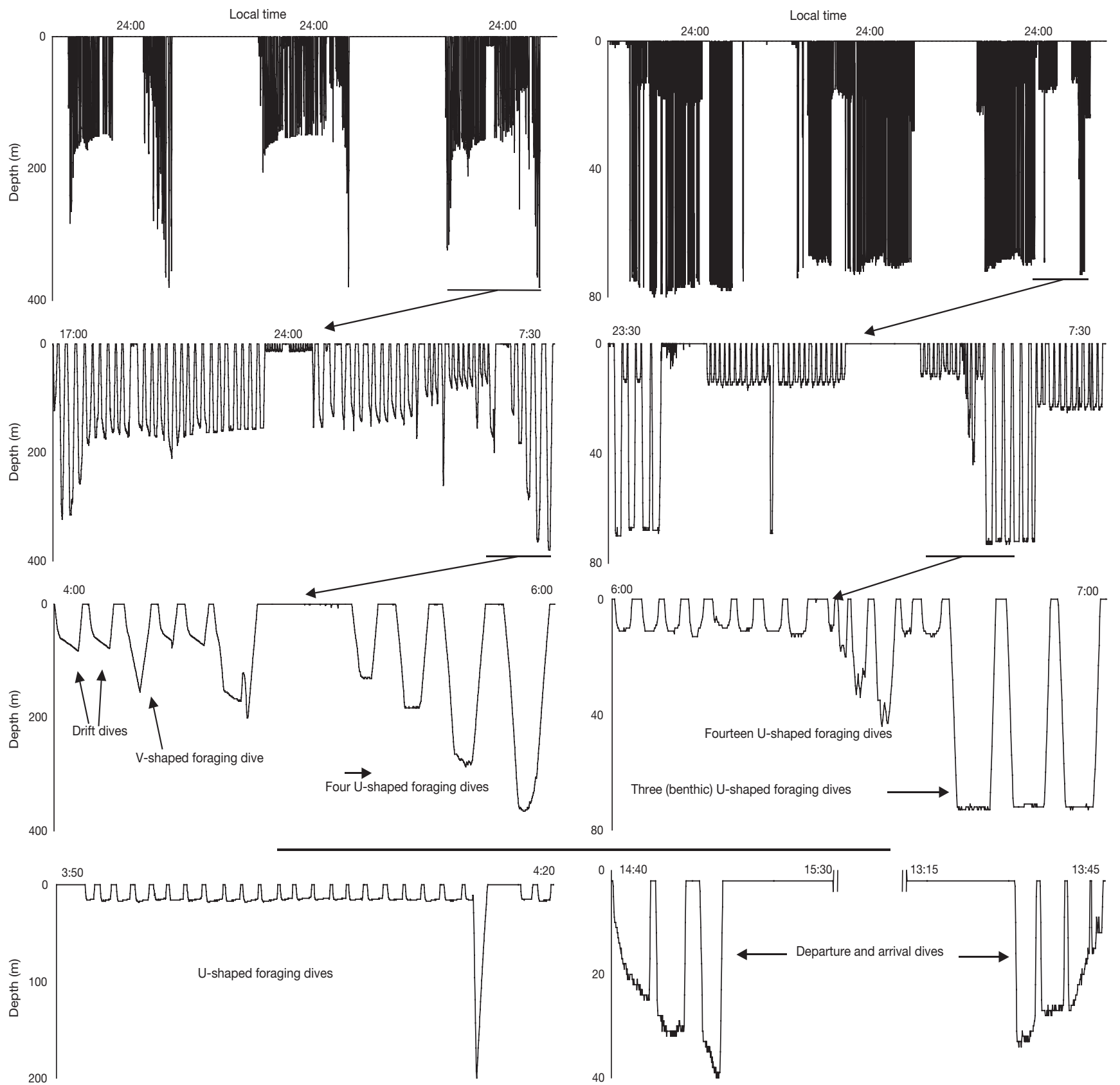

Fig. 2. Arctocephalus forsteri. Two-dimensional dive profiles in various resolutions from 2 adult NZ fur seals. Left panels: adult Male 270, right panels: adult Female 15 (Table 1). Dive profiles have resolutions of $2.5 \mathrm{~d}$ (top row), $14.5 \mathrm{and} 8 \mathrm{~h}$ (second row), 2 and $1 \mathrm{~h}$ (third row) and 30 and $80 \mathrm{~min}$ (bottom row). Putative U-shaped foraging and $\mathrm{V}$-shaped foraging, departure and arrival dives are indicated

was employed to determine the number of dimensions to use in MDS analyses. Principal-axes correlation was used to determine the most influential variables in MDS analyses. Principal-axes correlation takes the variables (diving parameters) and finds the location of the best-fitted vector in the ordination space. Variables with significant correlation coefficients, $r$, were re- corded. Stress values were calculated to give an indication of how well the data were represented during ordination. The stress in an MDS is a measure of how distorted (or scattered) the data are, after being confined to a limited number of vectors. The lower the stress value, the better the MDS representation of the data. Generally, stress values less than 0.10 are 


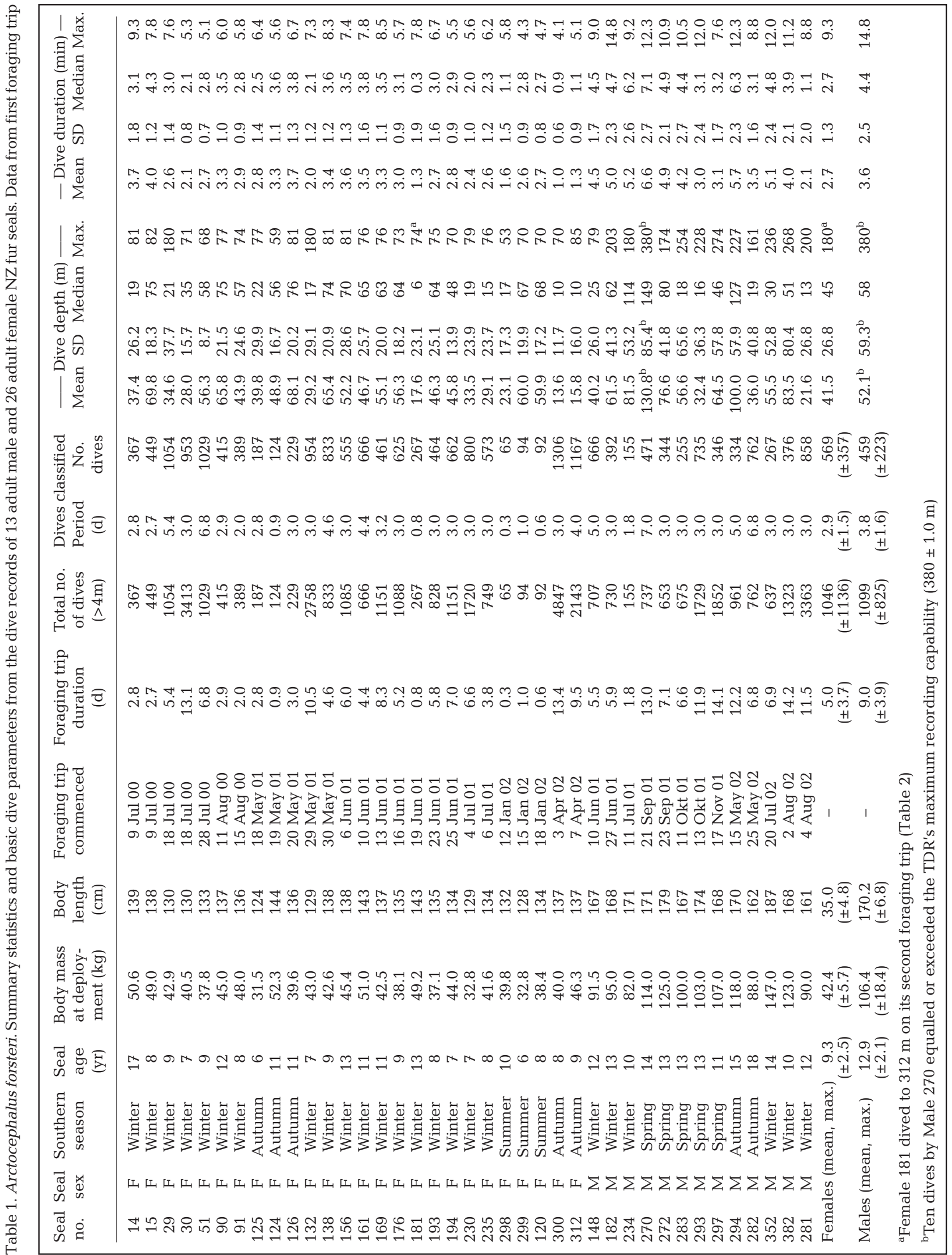


regarded as being unlikely to result in misinterpretation of the data (Schiffman et al. 1981).

Discriminant function analyses (DFA) were also used to compare differences between individuals' diving parameters. DFA indicates variation by showing the proportion of individuals that are correctly assigned back to their original groups based on the diving parameters. A stepwise DFA was used with minimisation of Wilk's $\lambda\left(F_{\mathrm{IN}}=3.84, F_{\mathrm{OUT}}=2.71\right)$ as the selection criterion for variables to be included in a function. Cross-validation was performed to verify the precision of the groupings.

Means are presented as \pm SD (standard deviation) and all statistical tests are 2-tailed, unless stated, with the $\alpha$ level of statistical significance set at 0.05 .

\section{RESULTS}

In total, 41477 dives were analysed from the first foraging trip made by 26 adult female (27 193 dives) and 13 adult male (14 284 dives) NZ fur seals (Table 1). The maximum dive durations and depths were $9.3 \mathrm{~min}$ and $312 \mathrm{~m}$ (females) and $14.8 \mathrm{~min}$ and $>380 \mathrm{~m}$ (males10 dives equalled or exceeded a TDR's maximum depth recording capability) (Table 1).

Adult females were significantly shorter and lighter than males (length: $t=16.42, \mathrm{df}=37, \mathrm{p}<0.001$, weight: $t=18.68, \mathrm{df}=37, \mathrm{p}<0.001)$ (Table 1). All of the adult males studied defended breeding territories in at least 1 of the following 4 breeding seaons (2001/2 to 2004/5), indicating that they were physically and socially mature males. Ages ranged from 6 to $17 \mathrm{yr}$ for adult females (average $=9.3 \pm 2.5$ ) and 10 to $18 \mathrm{yr}$ for adult males (average $=12.9 \pm 2.0$ ) $($ Table 1$)$. Adult males made significantly longer duration foraging trips than females $(t=3.17, \mathrm{df}=37, \mathrm{p}=0.003$ ) (Table 1$)$, however the total number of dives recorded per trip did not differ significantly $(t=0.15, \mathrm{df}=37, \mathrm{p}=0.882)$, in part because males made significantly longer-duration and deeper dives than females (duration: $t=5.06, \mathrm{df}=37$, $\mathrm{p}<0.001$, depth: $t=2.78, \mathrm{df}=37, \mathrm{p}=0.008)($ Table 1 ).

Most seals departed the colony in the afternoon and returned during the day (Fig. 3). Departure times

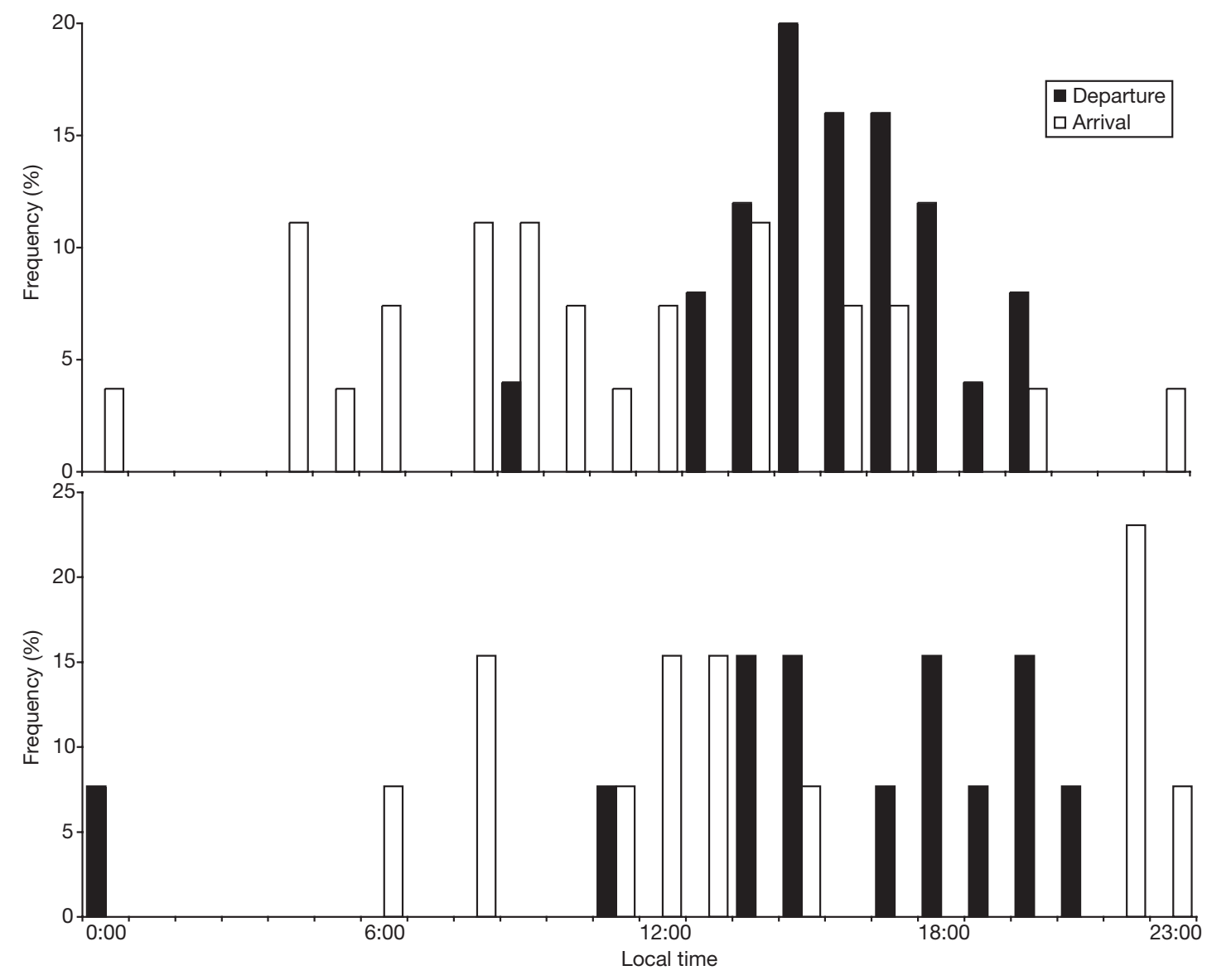

Fig. 3. Arctocephalus forsteri. Frequency distribution of arrival (white bars) and departure times (black bars) (local time), calculated from the dive records of 26 adult female (top) and 13 adult male (bottom) NZ fur seals. Data from first foraging trip 
were normally distributed for both females $(Z=1.88$, $\mathrm{p}=0.002)$ and males $(Z=1.94, \mathrm{p}=0.001)$, with most departures between 13:00 and 21:00 h (Fig. 3). At the start of their first foraging trip $73 \%$ of females and $92 \%$ of males made a series of 1 to 4 dives that appeared to be departure dives (Fig. 2). The mean time from departure until the first foraging dive for females and males was $2.71 \pm 2.36 \mathrm{~h}$ and $3.03 \pm 2.80 \mathrm{~h}$. Dives ceased $4.89 \pm 3.34 \mathrm{~h}$ (females) and $4.84 \pm 3.40 \mathrm{~h}$ (males) before arrival at the colony. A series of 2 to 6 arrival dives (Fig. 2) were made by $92 \%$ of females and $100 \%$ of males at the end of their first foraging trip. Arrival times were more variable than departure times, with most arrivals between 08:00 and 17:00 h (Fig. 3) and very few between midnight and 04:00 h. Male and female departure and arrival times were not significantly different (departure: $t=0.37, \mathrm{df}=37, \mathrm{p}=0.714$, arrival: $t=0.04, \mathrm{df}=37, \mathrm{p}=0.966$ ).

As a proportion of the number of foraging dives, V-shaped dives made up $15.6 \pm 18.2 \%$ (females) and
$20.0 \pm 18.8 \%$ (males) and U-shaped dives accounted for $84.4 \pm 18.4 \%$ (females) and $79.4 \pm 18.2 \%$ (males) On their first foraging trips, 6 males made a total of 147 drift dives $(0.6 \pm 0.4 \%$ of all dives) (Fig. 2), none of which were present in female dive records (Page et al. 2005b).

Foraging trip duration was not significantly different between seasons for either sex ( $p>0.05$ in all cases). Female foraging trip duration was significantly, positively correlated with the dive frequency (trip: $\mathrm{r}^{2}=0.46$, $\mathrm{n}=26, \mathrm{p}=0.018$; night: $\mathrm{r}^{2}=0.49, \mathrm{n}=26, \mathrm{p}=0.012$; day: $\mathrm{r}^{2}=0.40, \mathrm{n}=26, \mathrm{p}=0.042$ ) and significantly, negatively correlated with the mean dive duration at night (night: $\mathrm{r}^{2}=-0.41, \mathrm{n}=26, \mathrm{p}=0.037$ ). No other diving variables nor seal age, length or mass were significantly correlated to female foraging trip duration ( $p>0.05$ in all 40 cases) and none were significantly correlated to male foraging trip duration ( $\mathrm{p}>0.05$ in all 42 cases).

One female (Seal 30, Table 1) recorded a significantly greater proportion of DBT during the day (ANOVA, p <

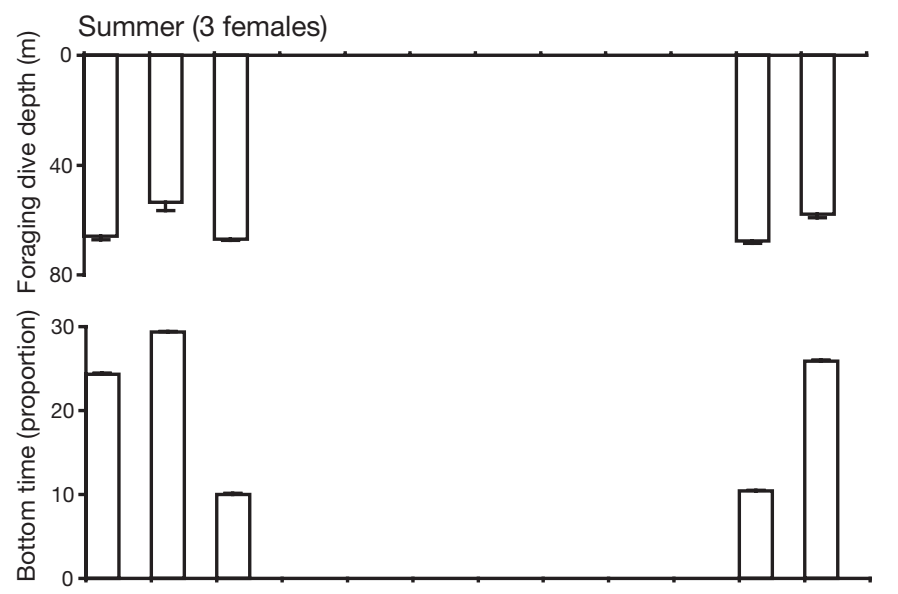

Autumn (5 females, 2males)
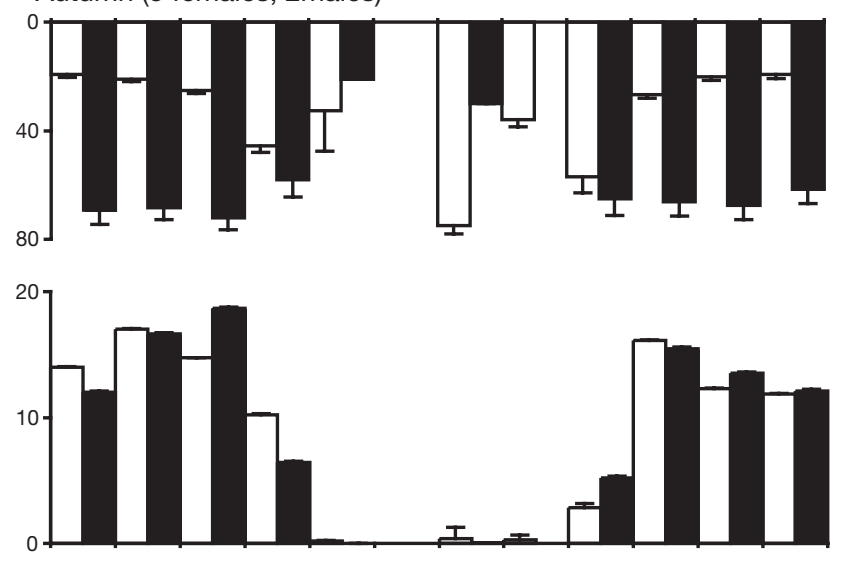

Spring (5 males)
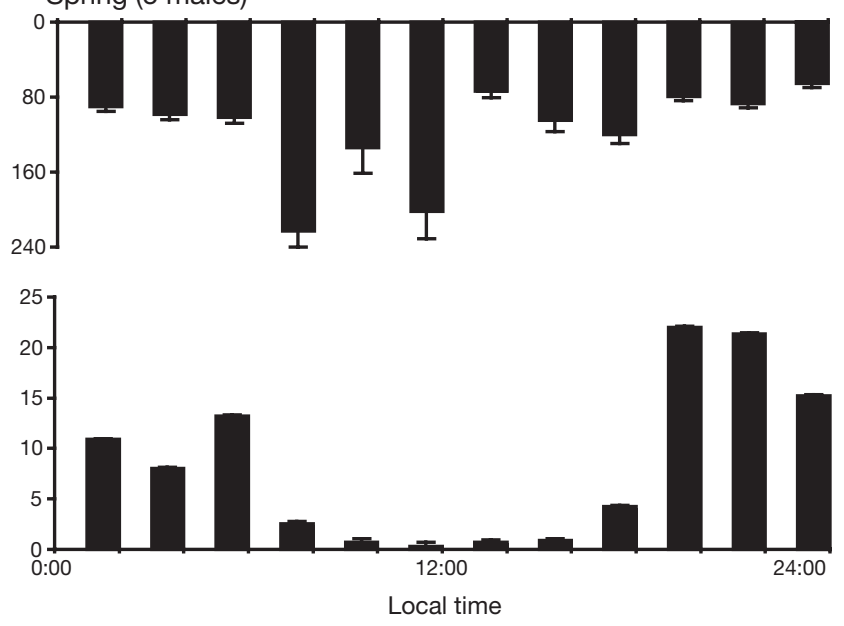

Fig. 4. Arctocephalus forsteri. Mean dive depths and the mean proportion of DBT in relation to local time and season for 26 adult female (white bars) and 13 adult male (black bars) NZ fur seals. Data from first foraging trip. Standard error bars are shown 
0.05) (Fig. 4). The proportion of DBT was significantly greater at night than during the day for 38 of the 39 seals (ANOVA, $p<0.05$ in all 38 cases). Dives were typically deeper around sunset and sunrise than they were around midnight (e.g. Fig. 2 top left plot), but many seals did not display such patterns (e.g. Fig. 2 top right). The diel variation in dive depth was most pronounced in female dive records during autumn (Fig. 4).

Inter-sexual comparisons of dive depth and the proportion of DBT were limited to autumn and winter, because no males were studied in summer and no females were studied in spring (Fig. 4). When data from day and night were combined, male dive depth was significantly greater than female (ANOVA, $\mathrm{p}<0.01$ in autumn and winter) (Fig. 4). During daylight hours in autumn, male dive depth was not significantly dif- ferent to female (ANOVA, $\mathrm{p}=0.389$ ), but during the day in winter, males dived significantly deeper (ANOVA, p = 0.042) (Fig. 4). During the night in autumn, male dive depth was significantly deeper than female (ANOVA, $p=0.002$ ), but in winter there was no significant difference (ANOVA, $\mathrm{p}=0.22$ ) (Fig. 4). The proportion of dives at night and during the day did not differ significantly between males and females in either autumn (ANOVA, p > 0.59) or winter (ANOVA, $\mathrm{p}>0.49$ ) (Fig. 4).

On average, females spent $99.7 \pm 0.3 \%$ of their DBT at $<80 \mathrm{~m}$ depth, compared with $51.6 \pm 14.8 \%$ for males (Fig. 4). Males spent most of their DBT between 0 and $20 \mathrm{~m}$ and 80 and $200+\mathrm{m}$, whereas females spent most of their DBT between 0 and $20 \mathrm{~m}$ and 40 and $80 \mathrm{~m}$ (Fig. 5). The depths at which females spent DBT were
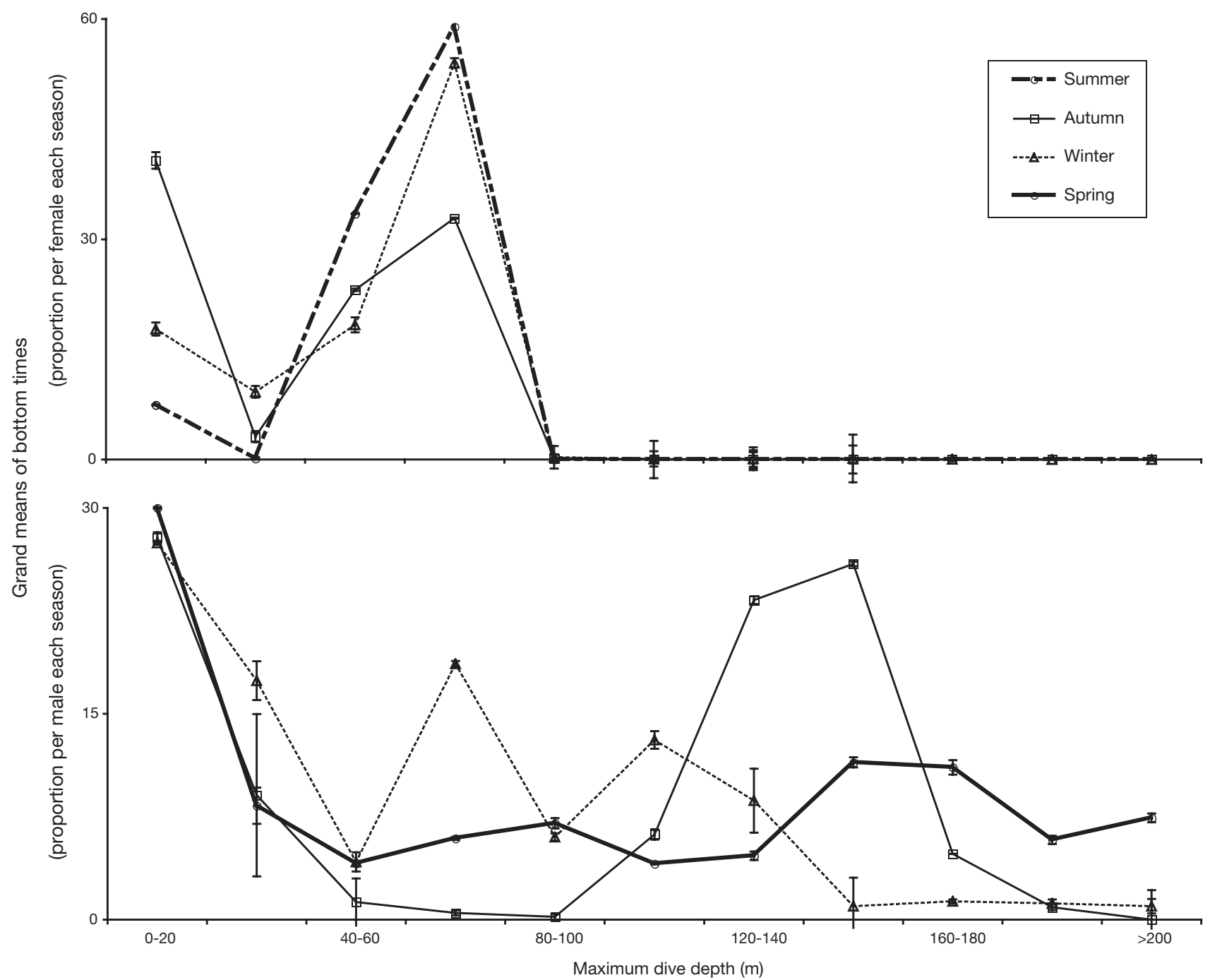

Fig. 5. Arctocephalus forsteri. Mean proportions of DBT spent in $20 \mathrm{~m}$ depth intervals during each season for 26 adult female (top) and 13 adult male (bottom) NZ fur seals (see Fig. 4 for sample sizes in each season). Data from first foraging trip. Standard error bars are shown 
similar in each season, with peaks at 0 to 20,40 to 60 and 60 to $80 \mathrm{~m}$ (Fig. 5). In autumn, females spent more DBT at 0 to $20 \mathrm{~m}$ and less at 60 to $80 \mathrm{~m}$, compared with winter and summer (Fig. 5). The lowest proportion of DBT at 0 to $20 \mathrm{~m}$ was recorded in summer, when females spent more time at 40 to $80 \mathrm{~m}$ (Fig. 5). Males spent approximately $28 \%$ of DBT between 0 and $20 \mathrm{~m}$ in each season and 8 to $17 \%$ of DBT between 20 and $40 \mathrm{~m}$, depending on the season (Fig. 5). In autumn, males spent $49 \%$ of DBT at 120 to $160 \mathrm{~m}$ and, other than 0 to $20 \mathrm{~m}$, little time at other depths (Fig. 5). In winter, males spent 6 to $19 \%$ of DBT at depth ranges between 60 and $120 \mathrm{~m}$ and little time beyond $120 \mathrm{~m}$ (Fig. 5). In spring, males spent a similar proportion of DBT in each depth range from 20 to $200+\mathrm{m}$, with a peak at 140 to $180 \mathrm{~m}$ (Fig. 5).

The results of MDS analyses show the similarity of individuals' diving parameters to other individuals' parameters (Fig. 6). Each individual's foraging trip is represented as a single point and different numbers represent seasons. The scree plot indicated that the multivariate analyses had grouped seals into 3 significantly different behavioural dive groups (BDG), which are enclosed by polygons in the MDS plot (Fig. 6). Seals that spent a significant amount of time foraging during the day (DAYTIME, $\mathrm{n}=4$ ) were first to be separated (Fig. 6, Table 2). The second BDG mainly foraged at night and DEEP $(\mathrm{n}=23)$, while the third BDG largely foraged at night but SHALLOW ( $\mathrm{n}=12$ ), indicating that DAYTIME and SHALLOW divers are the least similar groups (Fig. 6, Table 2). Up to 3 significantly correlated variables are shown for each end of each axis (Fig. 6) and the mean values of each BDGs variables are shown in Table 2 . Of the most significantly correlated variables, 10 (67\%) (Fig. 6) indicated different activity levels during the day and night: mean number of wiggles $\mathrm{h}^{-1}$ (day, night), dive frequency (day, night), proportion of hours at the bottom (day, night), proportion of hours submerged (day, entire trip), mean dive duration (day) and mean dive depth (day) (Table 2). Of the most significantly correlated variables, 5 (33\%) (Fig. 6) distinguished seals that dived DEEP from those that dived SHALLOW, for example: mean ascent rate (day), vertical depth $\mathrm{h}^{-1}$, mean ascent rate (night), mean descent rate (night, entire trip) (Table 2). The discriminant function analysis (DFA) assigned 97.4\% (92.3\% cross-validated) of individuals to the correct BDG based on the diving variables.

Neither seal age, length nor mass varied significantly as functions of BDG for males or females (ANOVA, $p>0.05$ ). There was no significant difference in the proportion of males to females in BDG $\left(\chi^{2}=3.67, \mathrm{df}=2\right)$. However, the relatively discrete groups formed by each sex indicate low levels of intrasexual variation relative to levels of inter-sexual variability (Fig. 6). The DFA was employed to further quantify inter-sexual differences. The DFA assigned $100 \%$ (97.4\% cross-validated) of seals to the correct sex based on the diving parameters. Sex-based differences indicated that females had higher dive frequencies, covered more vertical distance $\mathrm{h}^{-1}$, had faster rates of change in depth and had more but smaller wiggles compared with males (Table 2).

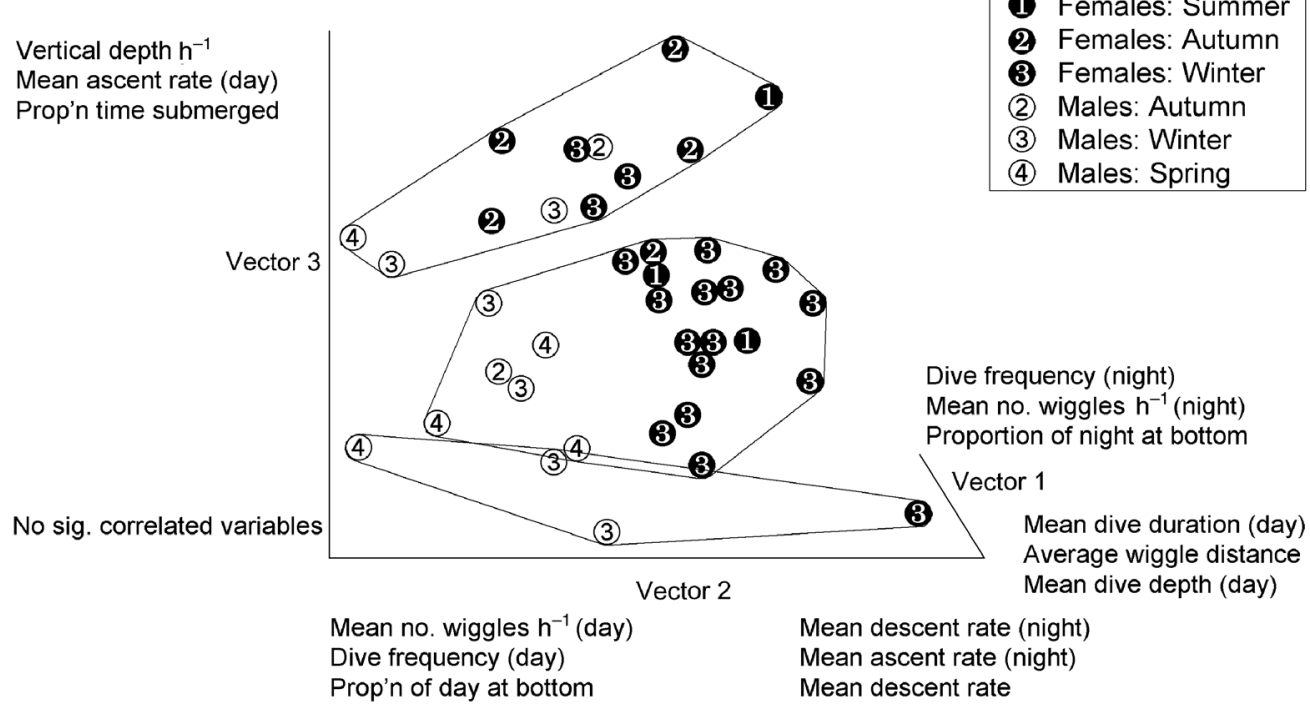

Fig. 6. Arctocephalus forsteri. Intra-sexual, inter-sexual, intra-seasonal and inter-seasonal variation in adult male (white points) and female (black points) NZ fur seal diving behaviour. Each individual's foraging trip is represented by a single point. Polygons enclose the 3 behavioural dive groups: DAYTIME (bottom polygon), DEEP (middle) and SHALLOW (top). Variables (diving parameters) that had significant correlation coefficients are shown on the ends of each axis. Three-dimensional stress $=0.077$ 
No significant inter-annual differences in BDG allocation were found. One significant seasonal difference was found in winter (all winters combined), when proportionally more females were grouped in BDG DEEP than SHALLOW or DAY $\left(\chi^{2}=16.33\right.$, df $\left.=2\right)$ (Fig. 6). Another (nonsignificant) trend was apparent for females in autumn (all autumns combined), when a high proportion of females were clustered in BDG SHALLOW $\left(\chi^{2}=3.67, \mathrm{df}=2\right.$ ) (Fig. 6 ). MDS and statistical analyses did not reveal any trends in the allocation of males to BDG (Fig. 6). However, DFA assigned $74.4 \%$ (56.4\% cross validated) of seals to the correct season, which is slightly higher than that might be expected by random allocation $(33 \%)$.

Table 2. Arctocephalus forsteri. Diving parameter, seal mass, seal length, seal age and foraging trip duration summaries for the 3 behavioural dive groups identified by MDS for adult male and female NZ fur seals. Panels separate diving parameters into combined day and night periods (top), night hours only (middle) and daylight hours only (bottom). Data from first foraging trip

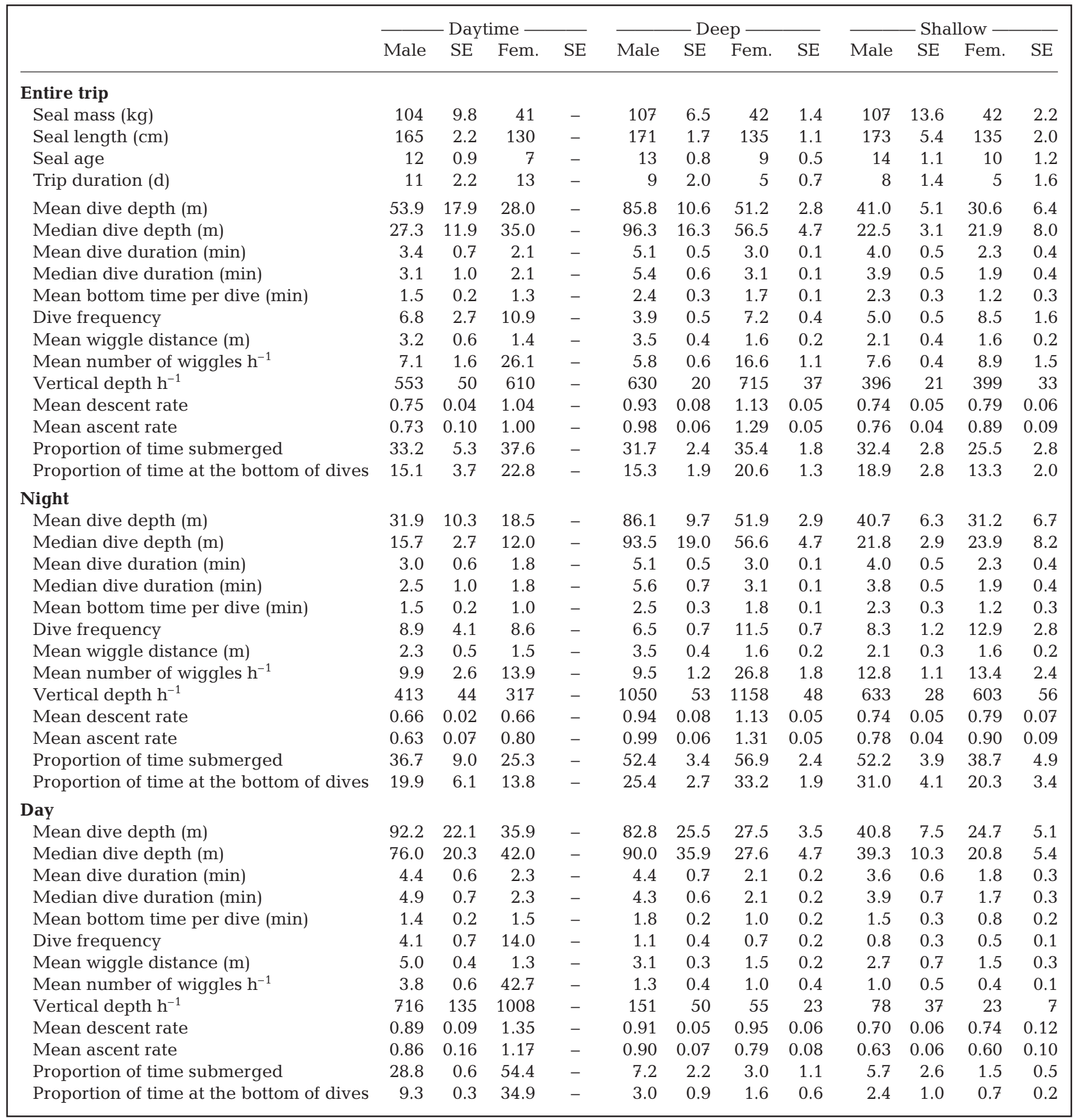




\section{DISCUSSION}

This is the first study to describe adult male NZ fur seal diving behaviour. The males in this study recorded the longest dive durations (maximum $14.8 \mathrm{~min}$ ) (Table 1) of the fur seals and sea lions studied to date. The deepest dives by female fur seals were also recorded (Table 1), reinforcing previous findings that NZ fur seals are among the deepest diving fur seals, with the longest dive durations (Mattlin et al. 1998).

Previous studies comparing the foraging behaviour of males and females in sexually dimorphic seal species have identified that males and females utilise different foraging space, both horizontally and vertically (different depth ranges) (e.g. Boyd et al. 1998, Le Boeuf et al. 2000, Campagna et al. 2001, Beck et al. 2003). Similarly, our results demonstrate marked differences between adult male and female diving behaviour, which also indicates spatial segregation in foraging. We found that most NZ fur seal females (92\%) restricted their maximum dive depths to $<90 \mathrm{~m}$, while most adult males $(92 \%)$ frequently went below $90 \mathrm{~m}$ (Table 1). The flat-bottomed appearance of some deep dives (e.g. female in Fig. 2) suggests that they were constrained in depth by the seafloor. Although the exact depth is not known where each seal dived, we estimate (based on dive depth and visual inspection of dive profiles) that when they foraged over the continental shelf or shelf break (B. Page unpubl. data), approximately $43 \pm 36 \%$ of female and $17 \pm 32 \%$ of male dives reached the seafloor. Together, these findings indicate that male and female NZ fur seals forage in different regions, with most females utilising continental shelf waters and most males using deeper, continental shelf break and/or pelagic waters (Fig. 1). Concurrent satellite tracking data corroborate these conclusions: the 24 adult females and 1 male foraged over the continental shelf, the 12 males foraged over the continental shelf break and the 2 females foraged in pelagic waters (Fig. 1) (B. Page unpubl. data).

Previous studies of land-breeding marine predators have suggested that prey would be less abundant in surface waters around colonies, compared to deeper and/or outlying areas (e.g. Ashmole 1963). However, central place foraging theory predicts that lactating fur seals would not utilise distant or deeper habitats, even if they contain less depleted prey resources than closer or shallower habitats, if the increased travel time required to exploit them (either horizontal or vertical) compromises their pups' fitness (Orians \& Pearson 1979). Ultimately a pup's fasting ability dictates when its mother returns from a foraging trip, except when prey are so scarce that returning to shore would compromise the mother's fitness. In accord with this, females in this study utilised prey in shallower, conti- nental shelf waters and undertook shorter duration foraging trips than males. Our findings support the idea that lactating female NZ fur seals are generalist predators, whose diet is influenced by both the prey available in their limited foraging range and the metabolic demands of gestation and lactation (Harcourt et al. 2002, Page et al. 2005a).

The continental shelf foraging habitats utilised by females do not appear to be exploited by many males, which swim over the shelf to forage in deeper waters over the shelf break. Prey such as small pelagic fishes are thought to be more concentrated over the shelf break, compared to the continental shelf (Shuntov 1969). Variables such as dive frequency, vertical depth $\mathrm{h}^{-1}$ and the proportion of time spent submerged have been used as indicators of dive effort in lactating fur seals (Boyd et al. 1991, Arnould et al. 1996, Arnould \& Hindell 2001, Lea et al. 2002), because they are central place foragers (Orians \& Pearson 1979). We demonstrated that females expended proportionally more dive effort (Table 3 ), possibly because they are restricted to foraging in what are most likely more heavily exploited waters, which males typically avoid. Alternately, such a pattern may simply reflect differences in the diving ability of males and females, as hypothesised by Mori \& Boyd (2004). However, the positive relationship between female NZ fur seal dive frequency variables and foraging trip duration and the negative relationship between female dive duration (night) and foraging trip duration suggests that females on shorter foraging trips made fewer, longer dives, compared with females on longer trips. This finding has also been demonstrated in Antarctic fur seals (Staniland et al. 2004). Females on shorter trips may invest less time searching for prey patches horizontally and more vertically, compared with females on longer trips (Boyd et al. 1991, Arnould et al. 1996, Arnould \& Hindell 2001). Our results suggest that females on longer trips utilised prey on frequent, brief dives. If it is true that prey are more depleted in the closer, shallower waters around Cape Gantheaume, our findings correspond with the theory of localised depletion, because seals that made short trips made longer dives in search of prey and vice versa.

Given that adult female fur seals are solely responsible for rearing pups, males might be expected to remain at sea during the non-breeding season, to maximise the time they spend foraging and their body mass. Such behaviour is demonstrated by male and female elephant seals, which only come ashore to breed and moult (Le Boeuf et al. 2000). However, male NZ fur seal foraging trips averaged just $9 \mathrm{~d}$, suggesting that a strategy of short trips followed by rests on land is typical of both males and females. Interestingly, males did not exhibit relationships between foraging trip 
duration and their dive variables, nor their age, length or mass, suggesting that trip duration was determined by other factors that we did not measure.

Although no studies have demonstrated how selection could favour the regular haulout strategy employed by male NZ fur seals, 3 reasons have been discussed: (1) the benefits of displaying to females and rivals during the non-breeding season, (2) delaying fat accumulation and (3) predator avoidance. Troy (1997) speculated that male NZ fur seals occupied their territories throughout the year to either display to females and influence female choice during the breeding season, or to display to rival males and reduce the need for physical fights during the breeding season. Although the mate choice hypotheses could not be tested, a greater proportion of males that occupied their territories during the non-breeding season subsequently held territories compared with other males. Although returning to territories may confer selective benefits on males, this does not explain why other males return to haulout sites, adjacent to breeding areas after similar short-duration foraging trips.

Selective benefits may also result if males can maintain a low body mass for as long as possible after the breeding season by postponing the accumulation of fat reserves until just prior to the breeding season. Such a strategy would reduce storage and transport costs during the year, which has been proposed to explain the seasonal differences in male grey seal Halichoerus grypus diving behaviour (Beck et al. 2003). Studies of male grey seals over extended periods indicate that they invest less dive effort and gain less mass $\mathrm{mo}^{-1}$ during the 5 mo after breeding, compared with the 4 mo prior to breeding (Beck et al. 2003). Although neither foraging trip duration nor measures of dive effort indicated that male NZ fur seals increased dive effort in the lead up to the breeding season, diet studies indicated that males consumed proportionally more highenergy fishes and little penguins Eudyptula minor and reduced their consumption of low-energy cephalopods (Page et al. 2005a), possibly employing a similar strategy to male grey seals.

Finally, if males inhabit waters with many potential predators, such as sharks, the need to avoid predators might explain why males come ashore to rest. Sleeping at the water surface may compromise males' security to such an extent that adequate rest is not achievable in areas where predators are common. Male NZ fur seals occasionally perform 'drift dives', when they possibly direct energy towards the processing of food, lactate or renal metabolites while resting underwater (Fig. 2, Page et al. 2005b), as has been suggested for elephant seals (Crocker et al. 1997). Although the function of drift dives remains unclear, selective benefits may also include predator avoidance and rest (Page et al. 2005b).
The near-shore dive patterns that characterised the start and end of foraging trips (Fig. 2) correspond with predator avoidance behaviour, which is also apparent in northern elephant seal and Australian fur seal dive records (Le Boeuf et al. 1988, Arnould \& Hindell 2001). Based on an adult population at Cape Gantheaume of approximately 2200 adult females and 850 adult males (Goldsworthy et al. 2003), which conduct foraging trips for 5 (females) and 9 (males) d (Table 1), then approximately 100 adult seals (and an unknown number of juveniles) traverse the waters around Cape Gantheaume each day, creating a potential hotspot for fur seal predators. The main predators of NZ fur seals are most likely great white sharks Carcharodon carcharias, bronze whaler sharks Carcharhinus brachurus and killer whales Orcinus orca, all of which are nearsurface predators that use visual cues to hunt (e.g. Riedman 1990) and occur around Cape Gantheaume (B. Page \& J. McKenzie pers. obs.). By flanking the seafloor around the colony and thereby reducing the time spent near the surface, seals may reduce the risk of detection by predators, particularly when commuting near the colony during the day or on bright nights.

The principle behind BDG analysis is that individuals in different BDG are assumed to utilise different prey. Although multivariate and other analyses identified marked sex-based differences in diving behaviour, the BDG were not delineated based on sex, suggesting that the behaviour of some males was more similar to some females' than to males' in other BDG and vice versa (Fig. 6). The analysis separated NZ fur seal BDG based on dive depth and time of day, similar to strategies identified in Antarctic fur seals (Lea et al. 2002). The nocturnal dive activity displayed by seals in BDG DEEP and SHALLOW is typical of fur seals and is thought to reflect the availability of prey, which move up in the water column to feed at night and migrate too deep for seals as day approaches (Gentry et al. 1986). By departing the colony to forage in the afternoon and returning during the day (Fig. 3), males and females maximise the proportion of night hours they spend at sea, consistent with nocturnal patterns of dive activity (Fig. 4). The dive parameters of seals in the DEEP BDG indicated that they dived deeper, for longer and covered greater vertical distances $h^{-1}$ at greater speeds than seals in the SHALLOW BDG (Table 2). Although we do not know the prey utilised by seals in each BDG, the seals in BDG DEEP presumably utilise a greater proportion of benthic prey. Dietary studies confirm that NZ fur seals forage near the benthos, with benthic fish and cephalopods comprising an average of $16.5 \%$ (seasonal range 2.0 to $31.9 \%$ ) and $19.7 \%$ (range 3.8 to $37.3 \%$ ) of the estimated prey biomass for females and males, respectively (Page et al. 2005a). 
In fur seal foraging behaviour studies, daytime divers typically comprise a small proportion of individuals; however, the strategy is present in several species (e.g. Goebel et al. 1991, Mattlin et al. 1998, Arnould \& Hindell 2001, Lea et al. 2002). Although prey over the continental shelf most likely remain within the reach of NZ fur seals during the day, most seals dive at night, suggesting that prey are more accessible at night.

Seasonal variation in NZ fur seal dive behaviour was apparent in New Zealand, where females dived deeper, for longer, as the year progressed from summer to autumn to winter (Mattlin et al. 1998, Harcourt et al. 2002). Both studies suggested that females made shallow dives to utilise pelagic, vertically migrating prey and switched to deeper dives later in the year to utilise benthic prey. Around Cape Gantheaume, alongshore winds upwell nutrient-rich water onto the continental shelf and shelf break during summer and autumn (Ward et al. 2004). This results in increased primary, secondary and tertiary production compared with other seasons (Ward et al. 2004) and most likely influences the distribution and abundance of fur seal prey. Surprisingly, seasonal differences in adult male NZ fur seal diving behaviour were not apparent at Cape Gantheaume (Fig. 6), with dives to shallow and deep regions in all seasons (Figs. 4 \& 5). During summer and winter, female dive depths indicated that they utilised proportionally more benthic prey, while in autumn females utilised prey in shallower waters. We could not relate seasonal variation in female dive behaviour to seasonal changes in their diet, possibly because individual or spatial variation accounted for some of the diving behaviour or dietary differences.

Although NZ fur seals do not appear to forage in waters adjacent to the colony, they do forage on their return journeys, possibly increasing the observed dietary overlap between adult males and females. Diet studies based on scat and regurgitate analyses may over-represent prey taxa, which are consumed when seals are on their way back to land, because remains from these prey may be more frequently deposited on land than remains from prey consumed at distant foraging grounds. For example, if males utilised completely different prey for 8 nights in shelf break waters, but foraged in transit for 1 night over the continental shelf, dietary differences due to spatial separation of foraging habitats may be lost at sea and only differences in preferences or abilities to exploit prey would be represented on land. The concurrent fur seal diet study at Cape Gantheaume indicated that about two thirds of adult male and female prey comprised a similar biomass of the same species (Page et al. 2005a). Unfortunately, little is known about the distribution of fur seal prey species in southern Australia, so it is difficult to determine whether inter-sexual differences in fur seal diet are a result of their preferences, or abilities to exploit prey, or because they utilise segregated habitats with different prey. Nonetheless, vertical and horizontal separation of foraging habitats and observed dietary differences (Page et al. 2005a) reduce foraging competition between adult male and female NZ fur seals.

The ecological divergence hypothesis suggests that sexual dimorphism evolved because males and female otariids employ different diving behaviour to utilise their preferred prey. In contrast, otariid foraging ecology studies typically indicate that lactating females are generalist predators, whose diet and foraging behaviour are dictated by the prey available around the central place (Harcourt et al. 2002, Page et al. 2005a). Our results suggest that although females have the dive capacity to feed where the males feed, they are possibly less efficient at utilising the same prey as males. Furthermore, male otariids are larger than females of the same age, which is not expected under the ecological divergence hypothesis (Gittleman \& Van Valkenburgh 1997). The observed diving behaviour differences between males and females appear to be a consequence of size dimorphism, rather than the cause of it.

The intra-sexual competition hypothesis parsimoniously explains the observed differences in male and female diving behaviour. Male otariids sexually mature before they are large enough to compete with older, larger and/or more experienced territorial males (Troy 1997). These males fight vigorously with one another to acquire and defend breeding territories, where most matings occur (Bartholomew 1970, Troy 1997). Selection then favours large males because they have greater fasting capacities and, therefore, increased mating opportunities compared with smaller rivals (Bartholomew 1970, Troy 1997). Achieving prime condition requires that male otariids undertake longer duration foraging trips and travel further than lactating females. Once at foraging grounds, males' large body size and their capacity to dive deeper and spend longer underwater per dive than females may be necessary to utilise the larger and more energy-rich prey (Page et al. 2005a), which males require to attain and maintain a greater mass.

An understanding of the diving and foraging behaviour of unconstrained demographic groups, such as non-lactating adult females and sub-adult males, would aid in the interpretation of the selective forces that shape NZ fur seal diving behaviour. For example, if non-lactating adult females and sub-adult males do not forage over the shelf break, this may indicate that smaller individuals cannot efficiently capture and handle the prey that adult males utilise. Non-lactating adult females and sub-adult males would not be ex- 
pected to forage over the continental shelf, because prey may be more depleted in these areas, compared with distant or deeper habitats. In order to maximise their growth and fitness, non-lactating adult females and sub-adult males would be expected to conduct longer duration foraging trips and search out more profitable foraging grounds, which lactating females could not utilise. Such studies may further highlight the pup-rearing constraints on females or uncover additional size-related influences on fur seal foraging habitats, behaviours and diet.

Acknowledgements. We thank the enthusiastic researchers who worked with us on Kangaroo Island, particularly A. Morrissey, R. McIntosh and L. Einoder. We thank A. Maguire, D. Dowie and the other National Parks staff who helped tremendously with field logistics. We thank M. A. Lea and M. Hindell for assisting with dive analyses and the 3 reviewers for their encouragement and suggestions, which greatly improved this paper. This project was supported by the Sea World Rescue and Research Foundation, the South Australian Department for Environment Wildlife Conservation Fund, Australian Geographic and PADI Project AWARE. B.P. received the CSIRO Marine Research scholarship and an Australian Postgraduate Award to conduct this project.

\section{LITERATURE CITED}

Arnould JPY, Hindell MA (2001) Dive behaviour, foraging locations and maternal attendance patterns of Australian fur seals (Arctocephalus pusillus doriferus). Can J Zool 79: 35-48

Arnould JPY, Boyd IL, Speakman JR (1996) The relationship between foraging behaviour and energy expenditure in Antarctic fur seals. J Zool 239:769-782

Ashmole NP (1963) The regulation of numbers of tropical oceanic birds. Ibis 103:458-473

Bartholomew GA (1970) A model for the evolution of pinniped polygyny. Evolution 24:546-549

Beals EW (1984) Bray Curtis ordination: an effective strategy for analysis of multivariate ecological data. Adv Ecol Res $14: 1-55$

Beck CA, Bowen WD, McMillan JI, Iverson SJ (2003) Sex differences in the diving behaviour of a size-dimorphic capital breeder: the grey seal. Anim Behav 66:777-789

Boyd IL, Lunn NJ, Barton T (1991) Time budgets and foraging characteristics of lactating Antarctic fur seals. J Anim Ecol 60:577-592

Boyd IL, McCafferty DJ, Reid K, Taylor R, Walker TR (1998) Dispersal of male and female Antarctic fur seals (Arctocephalus gazella). Can J Fish Aquat Sci 55:845-852

Campagna C, Werner R, Marin MR, Karesh WR, Koontz F, Cook C, Koontz C (2001) Movements and location at sea of South American sea lions (Otaria flavescens). J Zool 257:205-220

Clutton-Brock TH, Guiness FE \& Aubon SD (1982) Red deer: behaviour and ecology of two sexes. Chicago University Press, Chicago

Costa DP (1991) Reproductive and foraging energetics of pinnipeds: implications for life history patterns. In: Renouf D (ed) Behavior of pinnipeds. Chapman \& Hall, London, p 300-338

Costa DP, Gales NJ (2000) Foraging energetics and diving behaviour of lactating New Zealand sea lions, Phocarctos hookeri. J Exper Biol 203:3655-3665

Crocker DE, Le Boeuf BJ, Costa DP (1997) Drift diving in female northern elephant seals: implications for food processing. Can J Zool 75:27-39

Fea NI, Harcourt R, Lalas C (1999) Seasonal variation in the diet of New Zealand fur seals (Arctocephalus forsteri) at Otago Peninsula, New Zealand. Wildl Res 26:147-160

Funston PJ, Mills MG, Biggs HC, Richardson PRK (1998) Hunting by male lions: ecological influences and socioecological implications. Anim Behav 56:1333-1345

Gentry RL, Kooyman GL, Goebel ME (1986) Feeding and diving behaviour of northern fur seals. In: Gentry RL, Kooyman GL (eds) Fur seals: maternal strategies on land and at sea. Princeton University Press, Princeton, NJ, p 91-78

Gittleman JL, Van Valkenburgh B (1997) Sexual dimorphism in the canines and skulls of carnivores: effects of size, phylogeny and behavioural ecology. J Zool 242:97-117

Goebel ME, Bengston JL, DeLong RL, Gentry RL, Loughlin TR (1991) Diving patterns and foraging locations of female northern fur seals. Fish Bull 89:171-179

Goldsworthy SD, Bulman C, He X, Larcombe J, Littnan C (2003) Trophic interactions between marine mammals and Australian fisheries: an ecosystem approach. In: Gales N, Hindell M, Kirkwood R (eds) Marine mammals and humans: towards a sustainable balance. CSIRO Publishing, Melbourne, p 62-99

Green K (1997) Diving behaviour of Antarctic fur seals, Arctocephalus gazella Peters, around Heard Island. In: Hindell MA, Kemper C (eds) Marine mammal research in the southern hemisphere, Vol 1. Status ecology and medicine. Surrey Beatty \& Sons, Chipping Norton, p 97-104

Harcourt RG, Schulman AM, Davis LS, Trillmich F (1995) Summer foraging by lactating female New Zealand fur seals (Arctocephalus forsteri) off Otago Peninsula, New Zealand. Can J Zool 73:678-390

Harcourt RG, Bradshaw CJA, Dickson K, Davis LS (2002) Foraging ecology of a generalist predator, the female New Zealand fur seal. Mar Ecol Prog Ser 227:11-24

Hindell MA, Pemberton D (1997) Successful use of a translocation program to investigate diving behaviour in a male Australian fur seal, Arctocephalus pusillus doriferus. Mar Mamm Sci 13:219-228

Kirkwood RJ, Gales N, Lynch, Dann P (2002) Satellite tracker deployments on adult male Australian fur seals, Arctocephalus pusillus doriferus: methods and preliminary results. Aust Mammal 24:73-83

Lea MA, Hindell M, Guinet C, Goldsworthy S (2002) Variability in the diving activity of Antarctic fur seals, Arctocephalus gazella, at Iles Kerguelen. Polar Biol 25:269-279

Le Boeuf BJ, Costa DP, Huntley AC, Feldkamp SD (1988) Continuous deep diving in female northern elephant seals, Mirounga angustirostris. Can J Zool 66:446-458

Le Boeuf BJ, Naito Y, Asaga T, Crocker DE, Costa DP (1992) Swim speed in a female northern elephant seal: metabolic and foraging implications. Can J Zool 70:768-795

Le Boeuf BJ, Crocker DE, Costa DP, Blackwell SB, Webb PM, Houser DS (2000) Foraging ecology of northern elephant seals. Ecol Monogr 70:353-382

Mattlin RH, Gales NJ, Costa DP (1998) Seasonal dive behaviour of lactating New Zealand fur seals (Arctocephalus forsteri). Can J Zool 76:350-360

Mori Y, Boyd IL (2004) Separation of foraging between two sympatric penguin species: does rate maximisation make the difference? Mar Ecol Prog Ser 275:241-249

Orians GH, Pearson NE (1979) On the theory of central place foraging. In: Horn DJ, Stairs BR, Mitchell RD (eds) Analysis of Ecological Systems. Ohio State University Press, 
Columbus, p 155-177

Page B, McKenzie J, Goldsworthy SD (2005a) Dietary resource partitioning among sympatric New Zealand and Australian fur seals. Mar Ecol Prog Ser 293:283-302

Page B, McKenzie J, Hindell MA, Goldsworthy SD (2005b) Drift dives by male New Zealand fur seals (Arctocephalus forsteri). Can J Zool 83:293-300

Radford AN, Du Plessis MA (2003) Bill dimorphism and foraging niche partitioning in the green woodhoopoe. J Anim Ecol 72:258-269

Riedman M (1990) The pinnipeds: seals, sea lions and walruses. University of California Press, Berkeley

Robson BW (2004) Separation of foraging habitat among breeding sites of a colonial marine predator, the northern fur seal (Callorhinus ursinus). Can J Zool 82:20-29

Schiffman S, Reynolds ML, Young FW (1981) Introduction to multidimensional scaling. Academic Press, New York

Shine R, Reed RN, Shetty S, Cogger HG (2002) Relationship between sexual dimorphism and niche partitioning within a clade of sea snakes (Laticaudinae). Oecologia 133:45-53

Shuntov VP (1969) Some features of the ecology of pelagic fishes in the Great Australian Bight. Probl Ichthyol 9: 801-809

Sol D, Santos DM, Cuadrado M (2000) Age-related feeding

Editorial responsibility: Otto Kinne (Editor-in-Chief),

Oldendorf/Luhe, Germany site selection in urban pigeons (Columba livia): experimental evidence of the competition hypothesis. Can J Zool 78:144-149

Staniland IJ, Reid K, Boyd IL (2004) Comparing individual and spatial influences on foraging behaviour in Antarctic fur seals Arctocephalus gazella. Mar Ecol Prog Ser 275: 263-274

Stewart BS (1997) Ontogeny of differential migration and sexual segregation in northern elephant seals. J Mammal 78: 1101-1116

Stewart REA, Stewart BE, Stirling I, Street E (1996) Counts of growth layer groups in cementum and dentine in ringed seals (Phoca hispida). Mar Mamm Sci 12:383-401

Troy SK (1997) Territorial behaviour and mating success in male New Zealand fur seals, Arctocephalus forsteri. PhD thesis, University of Melbourne

Ward TM, McLeay LJ, Dimmlich WF, Rogers PJ, McClatchie S, Matthews R, Kampf J, Van Ruth P (2004) Pelagic ecology of a northern boundary current system. In: Ward TM, Goldsworthy SD, Page B (eds) Trophodynamics of the GAB: assessing the need for an ecological allocation in the SA pilchard fishery. Fisheries Research and Development Corporation and South Australian Research and Development Institute, Adelaide, p 28-47

Submitted: February 23, 2005; Accepted: May 24, 2005 Proofs received from author(s): November 11, 2005 